\title{
A ESTRADA DE FERRO DE BRAGANÇA E A PRODUÇÃo DO ESPAÇO NA AMAZÔNIA: REFLEXÕES ACERCA DO MUNICÍPIO DE BENEVIDES (PA)
}

\author{
Luciano Andrade de SOUZA ${ }^{1}$
}

\section{Resumo}

A Estrada de Ferro de Bragança (1884-1964) teve forte influência junto a produção espacial do município de Benevides, no Pará. A forte influência da estrutura da EFB dinamizou a Região da Bragantina, assim como estimulou a criação de inúmeras colônias agrícolas, dentre as quais o presente trabalho foca na colônia agrícola de Benevides, a primeira a ser criada pela então Província do Pará. A referida colônia agrícola atraiu vários estrangeiros com experiências em agricultura, os quais vieram pra Amazônia em busca de oportunidades e atraídos pela propaganda realizada pelo governo provincial da época, o qual prometia prosperidade aos estrangeiros que colocassem em prática, na colônia agrícola de Benevides, sua experiência agrária.

Palavras-chave: Produção do Espaço, Colônia Agrícola de Benevides, Estrada de Ferro de Bragança.

\begin{abstract}
The Bragança Railroad (1884-1964) had a strong influence next to the space production of the county of Benevides, in Pará. The strong influence of the EFB structure dinamized the Bragantina Region, as stimulated the creation of innumerable agricultural colonyamong which the present work to focus on the agricultural colony of Benevides, the first to be created by then Province of Pará. The said agricultural colony attracted several foreigners with experiences in agriculture, which came to the Amazon in search of opportunities and attracted by the propaganda made by the provincial government of the time, which promised prosperity to the foreigners to put in practice, in the agricultural colony of Benevides, your agrarian experience.
\end{abstract}

keys-words: Space Production, Agricultural Colony of Benevides, Bragança Railroad.

\section{INTRODUÇÃO}

A história da Estrada de Ferro de Bragança (EFB), presente no Estado do Pará no período de 1884 a 1964, volta à tona pelas mãos de pesquisadores e estudiosos que valorizam o patrimônio existente na saudosa "Região da Bragantina", no Norte do Brasil. Foram oitenta anos de funcionamento e integração entre Belém e a cidade de Bragança. Porém uma gama de documentos e memórias sobre a EFB ainda estão por ser explorados, o que reforça ainda mais a importância de se resgatar a história dessa via férrea que, outrora, tanto dinamizou e produziu espaços ao longo de seus trilhos.

Trata-se de uma reunião de lembranças sem fim, como muito bem define Siqueira (2017), em seu ensaio "O caminho de ferro e seus ramais". Ela marcou um período,

\footnotetext{
${ }^{1}$ Mestre em Geografia pelo Programa de Pós Graduação em Geografia da Universidade Federal do Pará. E-mail: lucianoaulageo@gmail.com
} 
empreendendo um desenvolvimento econômico, onde a velocidade das máquinas ditava o ritmo do progresso, transportando o ser humano e o resultado do seu labor, interagindo e transformando os lugares a ela interligado pela sua gigantesca trilha férrea. A figura 1 abaixo nos evidencia a EFB e algumas colônias agrícolas ao longo do seu trajeto.

FIGURA1: Estrada de Ferro de Bragança e as colônias agrícolas ao longo de sua via férrea.

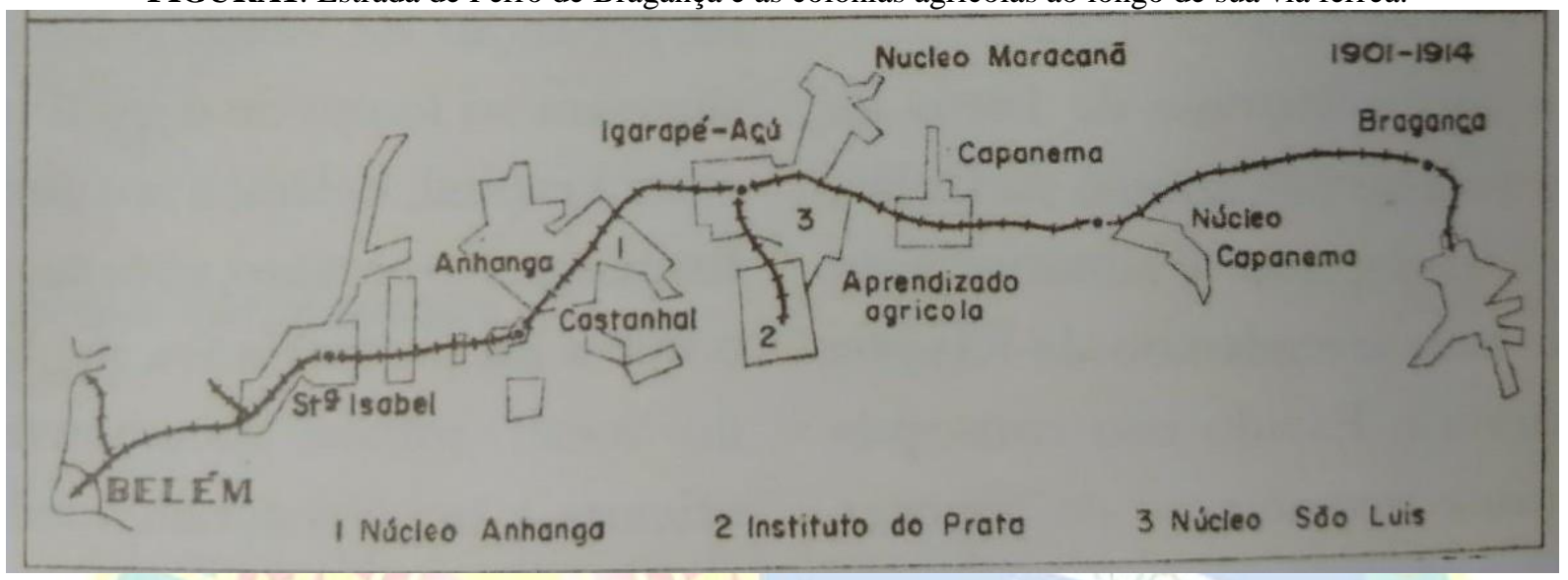

FONTE: Ferreira (2017).

A idéia do progresso estava plantada e amarrada às inúmeras ações que deram origem a agricultura, a colonização e a imigração. Tais ações desenvolveram-se em meio a floresta densa e inexplorada, a qual fora rasgada pelos trilhos que iriam, mais tarde, escoar todas as produções realizadas nas colônias agrícolas existentes no entorno da via férrea.

O presente artigo é fruto de uma revisão bibliográfica e documental acerca da história da EFB e sua influência na produção de espaços agrícolas ao longo de sua linha férrea, numa região conhecida pelo nome de Bragantina. Livros, artigos, álbuns históricos, jornais antigos e documentos históricos deram suporte para a realização de referido artigo.

O foco maior dentre os espaços influenciados pela EFB é a colônia agrícola de Benevides, a qual já existia, mesmo antes da construção da EFB. No entanto seu progresso e dinamismo crescem com a introdução de um trecho, em seu espaço, da EFB. Tal situação é explicada, sobretudo, pelo aumento da produção agrícola, dada a maior facilidade no escoamento de tal produção e pela infraestrutura gerada (estação ferroviária, residências com arquiteturas diferentes das que ali existiam, comércios, engenhos etc).

O referido trabalho encontra-se estruturado em tópicos distribuídos da seguinte forma: Na primeira parte é feita uma abordagem histórica sobre a instalação da colônia agrícola de Benevides e a influência da EFB em sua estruturação. Na segunda parte temos um 
tópico que fala da importância da Freguesia de Benfica, junto ao abastecimento da colônia agrícola de Benevides e também de Belém. Na terceira parte há um tópico que aborda a transformação da colônia agrícola de Benevides em município. E, por fim, um tópico com as considerações finais acerca da influência da EFB no que consiste na produção do espaço geográfico do município de Benevides.

\section{A COLÔNIA AGRÍCOLA DE BENEVIDES}

A cidade de Bragança, localizada no nordeste paraense, era a principal fornecedora de gêneros agrícolas e de pescado para a capital da Província (Belém). O fato de Bragança ficar geograficamente distante de Belém gerou a necessidade de se criar um núcleo agrícola mais próximo da capital, visto que as viagens de Bragança até Belém,realizadas por barcos e navios, eram muito demoradas e, por conseguinte, dificultavam a dinâmica do comércio em Belém.

O abastecimento do mercado belenense muitas vezes ficava desprovido de alguns gêneros agrícolas em virtude de sua dependência de Bragança. De fato, era necessário criar um núcleo agrícola mais próximo e que não deixasse faltar produtos no mercado belenense (CRUZ, 1955).

A produção do espaço na área central do nordeste paraense tem início antes da construção da EFB, com a fundação de um núcleo primitivo (1873), o qual originaria, posteriormente, a colônia de Benevides (1875), vanguarda da colonização, a qual teve em seu território colonos de inúmeras nacionalidades (franceses, americanos, holandeses, libaneses, turcos, etc.), além de brasileiros, principalmente, nordestinos, sobretudo maranhenses e cearenses(FERREIRA, 2017). Logo abaixo, na figura 2, podemos identificar, através de um mapa do município de Benevides, a sua atual localização. 
FIGURA 2: Mapa do município de Benevides (PA).

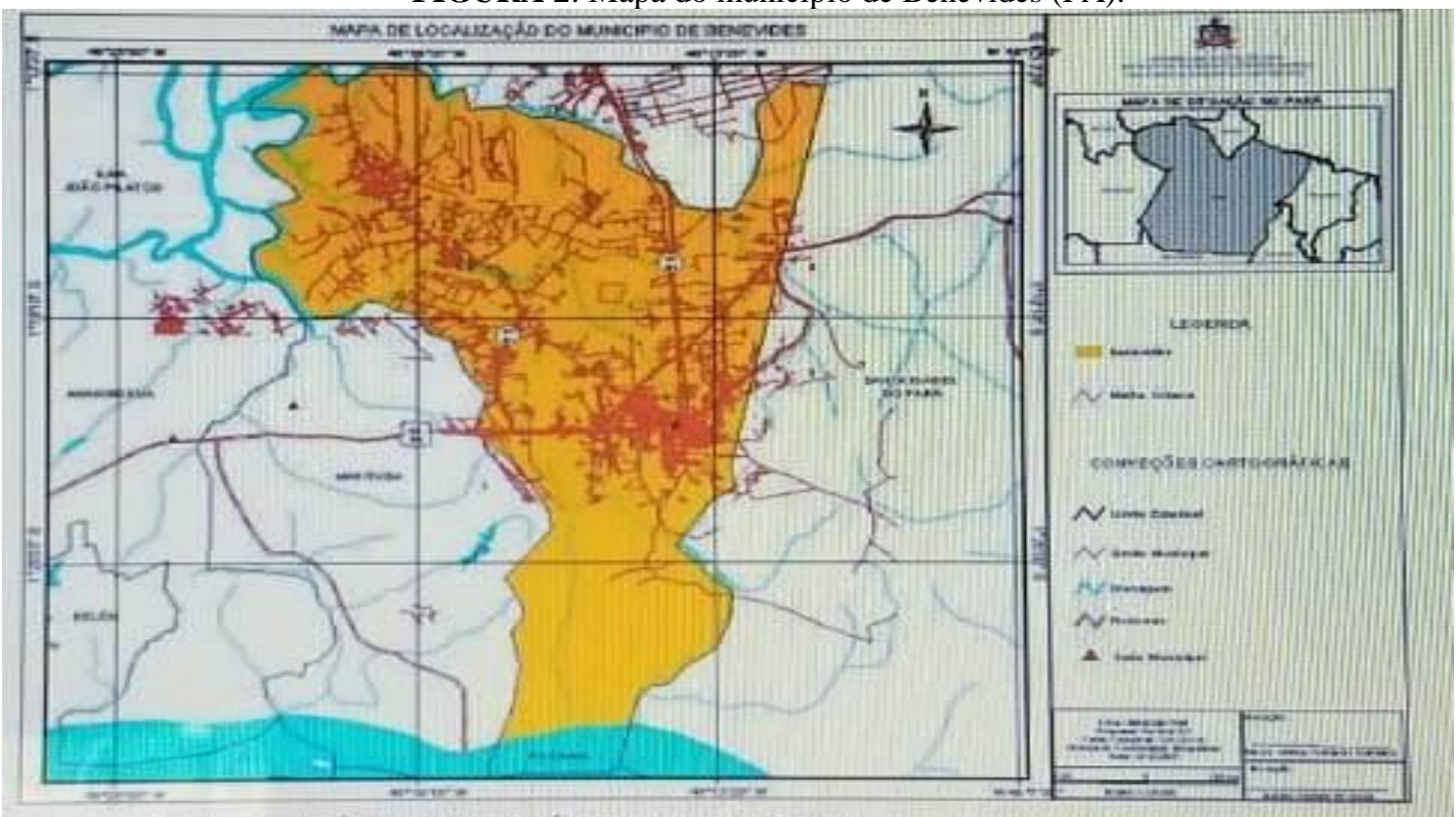

FONTE: Souza (2011)

Aos que se destinassem ao referido núcleo agrícola, segundo Cruz (1955), eram dados incentivos (concessão de um título provisório de um lote de terras, à livre escolha do colono; coleção de instrumentos indispensáveis à lavoura; sementes e alimentos durante seis meses etc.) para a plantação, assim como para a comercialização do produto colhido. A figura3,abaixo, ilustra a Casa dos Americanos, onde os mesmos habitavam, na época da colônia agrícola de Benevides.

FIGURA 3: Antiga Casa dos Americanos, localizada no centro de Benevides.

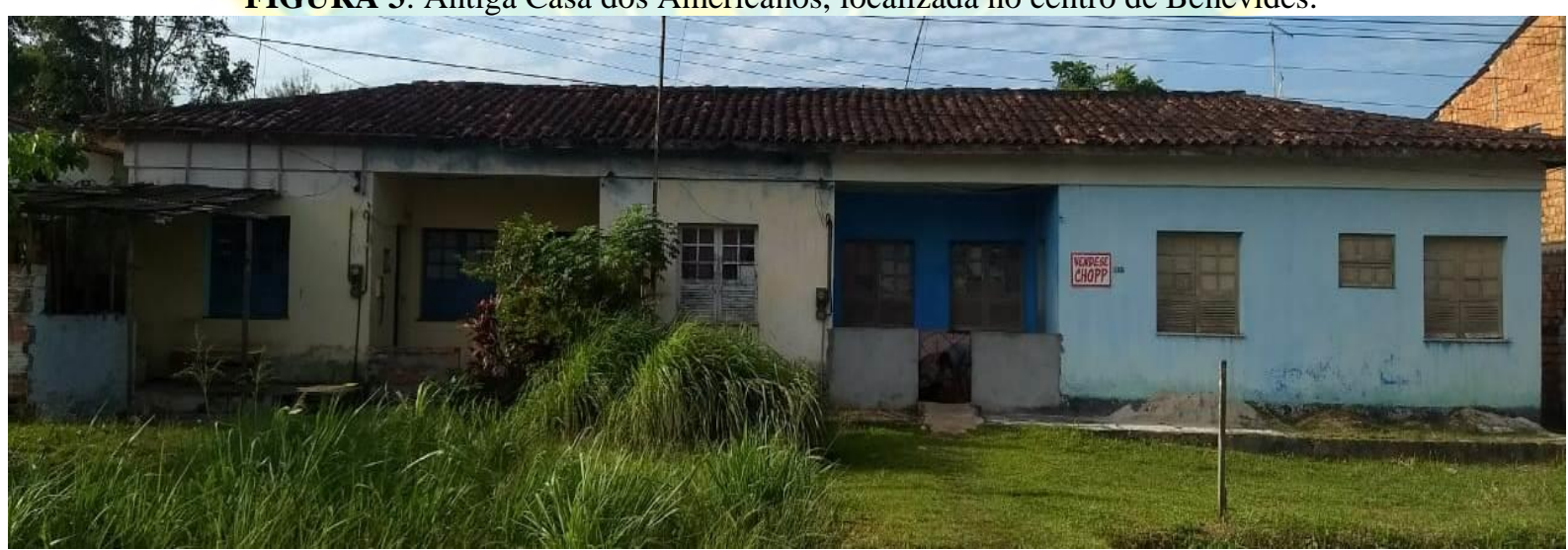

FONTE: Luciano Andrade de Souza (2018). 
A primeira colônia agrícola da EFB, a colônia de Benevides, foi inaugura em junho de 1875, pelo então Presidente Provincial Francisco Maria Corrêa de Sá e Benevides. Antecipada em oito anos, em relação a construção da EFB, serviu de expoente para o restante das colônias agrícolas que, ainda, iriam surgir na Zona Bragantina.

A colônia de Benevides recebeu, nos cinco primeiros meses, mais de 180 estrangeiros, que logo somariam um total de 364; porém mais da metade desses imigrantes não se adaptou ao clima e a situação inóspita da região. Em virtude de tal situação, dois anos após sua inauguração, mais da metade, em torno de 247 estrangeiros, abandonaram a colônia rumo à cidade de Belém (FERREIRA, 2017).

Em princípio, os estrangeiros não se adaptaram à região devido ao clima ser muito quente e os mesmos não terem recebido o apoio (boas residências, dinheiro para iniciar a produção agrícola, por exemplo) que o governo provincial havia lhes prometido, quando chegaram à colônia agrícola. Em seguida, o território onde foi criada a colônia não possuía um solo apropriado para plantar determinadas culturas, dificultando a variação nas plantações.

O forte na colônia consistia nos produtos típicos de uma agricultura familiar como mandioca, feijão, cana-de-açúcar, banana, etc. Outras culturas agrícolas não poderiam ser exploradas pelos estrangeiros, pois o solo não oferecia condições adequadas. Assim, a maioria dos estrangeiros abandonou o projeto do núcleo agrícola, ficando, no local, apenas alguns franceses, holandeses e libaneses(SANTIAGO; OLIVEIRA, 2005).

No mesmo período citado acima, mais precisamente 1877 , em virtude da forte seca que se abateu sobre aregião nordeste do Brasil, inúmeras pessoas (entorno de 10 mil), migraram dessa região para a, então, capital da Província (Belém). Diante de tal situação e, visando reativar a colônia agrícola de Benevides, o presidente da Província realocou os nordestinos na colônia agrícola de Benevides.

A maioria da população do referido núcleo ficou circunscrita aos nordestinos que permaneceram em seus lotes e procuraram trabalhar nas lavouras de cana-de-açúcar e em alguns engenhos. Alguns engenhos pertenciam a nordestinos e outros aos poucos estrangeiros que ainda ficaram.Segue abaixo a figura 4 evidenciando uma imagem atual do prédio onde se localizava o antigo engenho "Santa Sophia", o qual, atualmente, serve de espaço de moradia, o prédio data de 1844. 
FIGURA4:Antigo engenho Santa Sophia, de propriedade do nordestino Clovis Soares Bulcão.

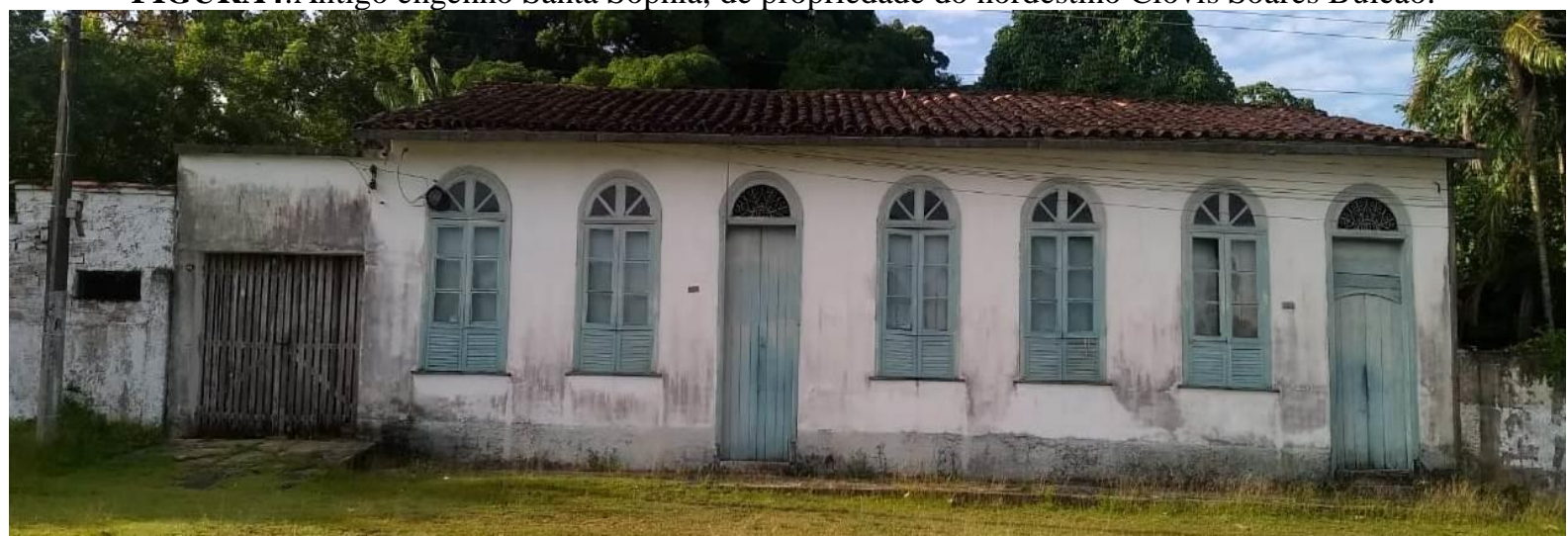

FONTE: Begot (1984).

A configuração espacial da colônia agrícola de Benevides recebe, em 1884, novas estruturas, em virtude da inauguração da EFB; dentre elas está construção da estação terminal ferroviária (em junho do mesmo ano). A construção da estação terminal facilitou, sobremaneira, o escoamento da produção agrícola da colônia para Belém, o qual antes era transportado via rio Benfica até o porto da capital. A seguir, na figura 5, podemos vislumbrar uma imagem que muito se aproxima da estrutura original da Estação Ferroviária da colônia de Benevides; tal imagem data de 1984.

FIGURA5: Antigo prédio da Estação Ferrovia em Benevides.

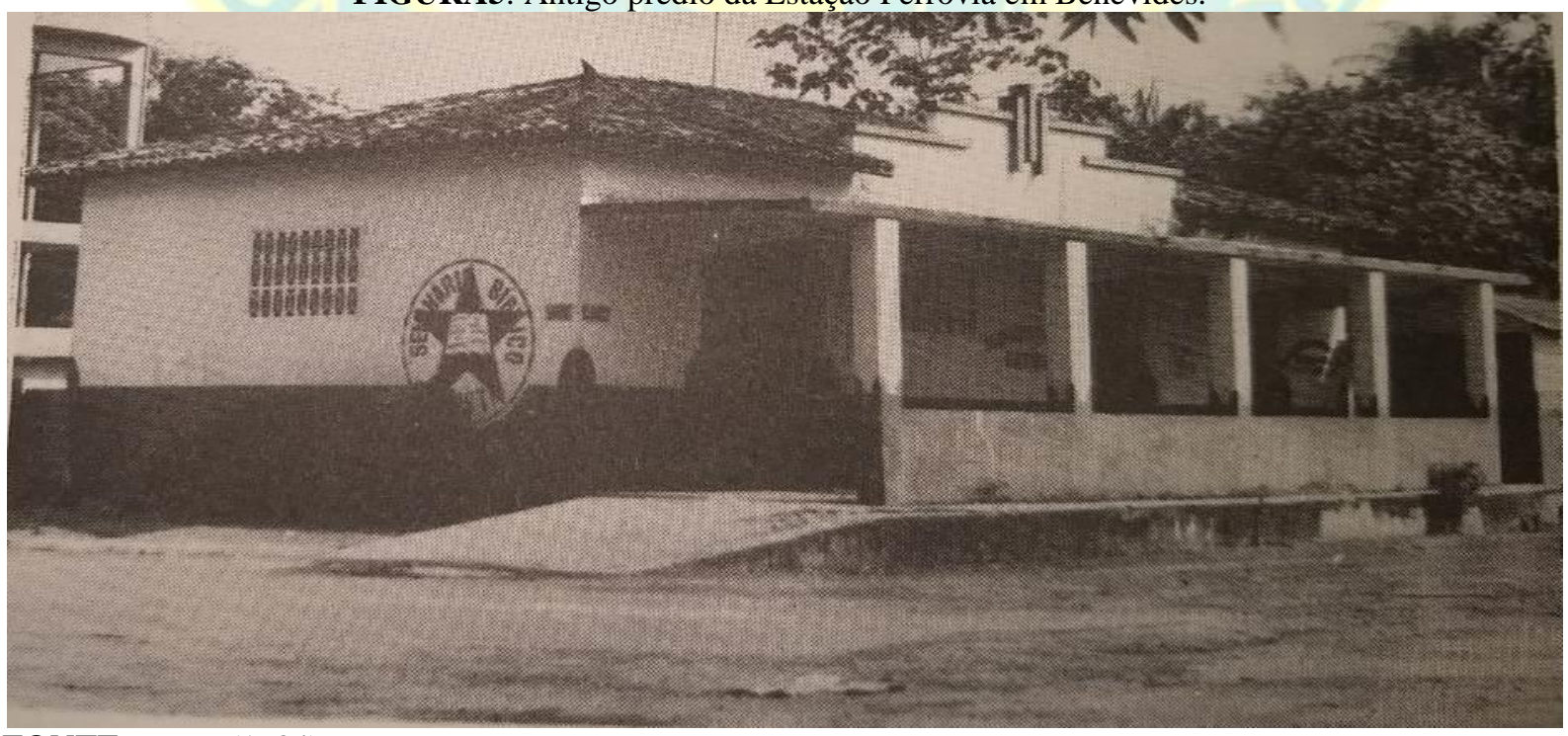

FONTE: Begot (1984). 
Os campos agrícolas da colônia de Benevides puderam aumentar sua produção, significativamente, com um fato histórico (libertação dos escravos dessa colônia, em 1884). A Sociedade Libertadora de Benevides, uma entidade jurídica local, objetivava segundo Ferreira (2017) libertar e abrigar os escravos existentes na região. Tal fato possibilitou o aumento da mão de obra nos campos, com a volta ao trabalho, agora livre, de ex-escravos fugitivos, o que impulsionou a produção local (BEGOT, 1984).

\section{A FREGUESIA DE BENFICA}

$\mathrm{O}$ atual distrito de Benfica, o qual pertence ao município de Benevides, era, no período da colônia agrícola de Benevides, uma Freguesia de Belém. Segundo Siqueira (2017), o transporte de passageiros do porto de Belém até o porto de Benfica via documento oficial de contrato de navegação foi efetivado em junho de 1879 com os comerciantes Farias e Barbosa, o qual teve a aprovação de uma Lei Provincial n ${ }^{\circ}$ 920. Mais tarde, em 1880, por sugestão do Ministério da Agricultura, outro contrato seria assinado, porém agora com outra empresa chamadaCompanhia de Navegação do Amazonas Ltda. Este novo contrato de navegação faria um percurso, dentre outros, de duas viagens semanais até o porto de Benfica.

A efetivação de tais contratos de navegação propiciou uma aproximação maior entre a colônia de Benevides e a cidade de Belém. Foi o primeiro passo na resolução do tão difícil acesso à colônia. O trecho entre a colônia de Benevides e o porto de Benfica era estreito e cheio de tormentas, o que dificultava o transporte das mercadorias produzidas na colônia. Tal trajeto era feito através de carroças. Em Benfica, havia um porto que recebia inúmeros carregamentos de mercadorias vindas da colônia de Benevides, assim como, de outras localidades mais próximas. Do porto, as mercadorias eram embarcadas e levadas em barcos pelo rio Benfica até a Baia do Guajará, chegando ao Vêr-o-Pêso em Belém (SANTIAGO; OLIVEIRA, 2005).A figura 6 abaixo retrata a praça central do distrito de Benfica, no ano de 1984, período em que estava em plena construção. 
FIGURA 6: Construção da praça matriz do distrito de Benfica.

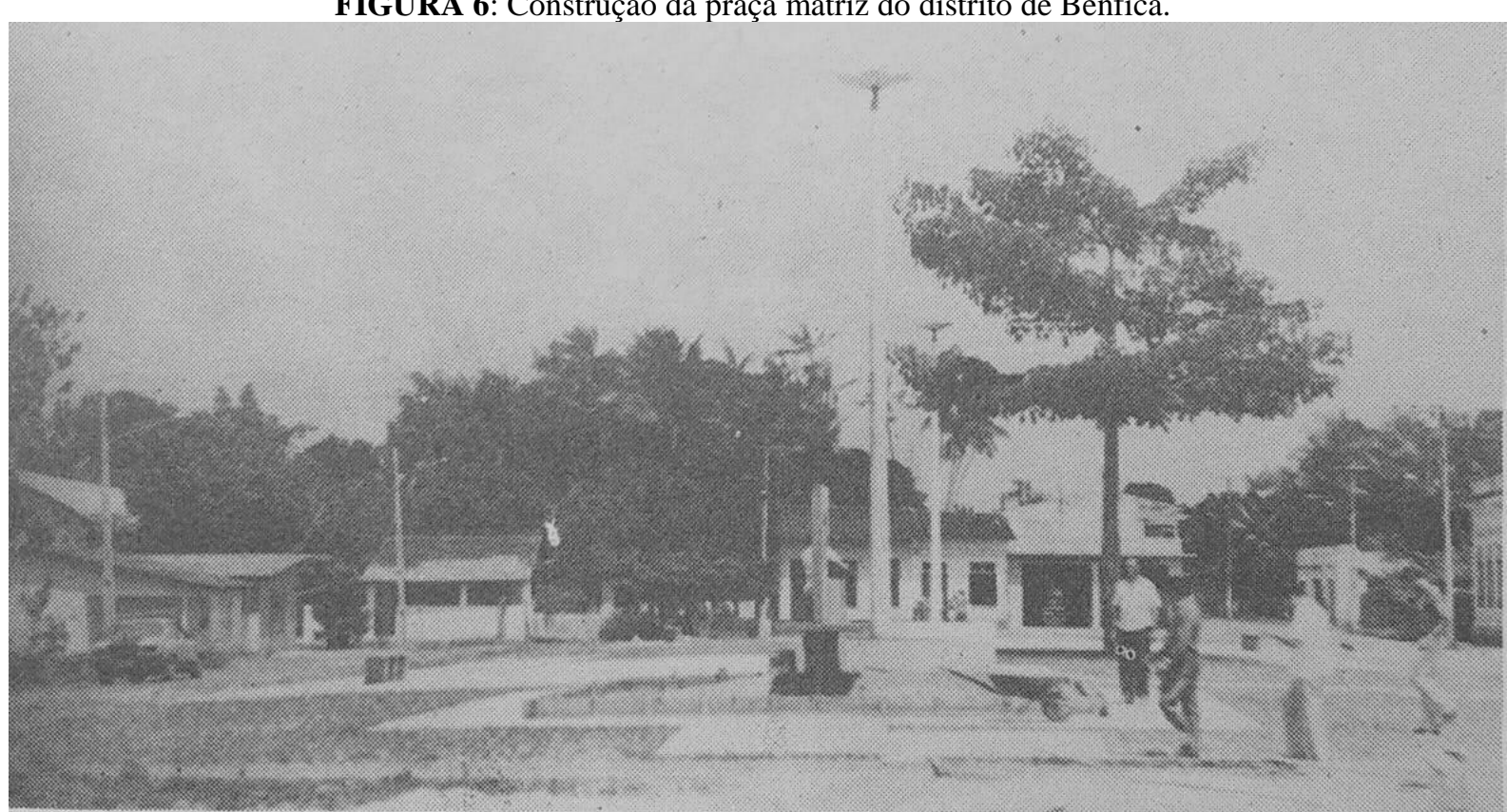

FONTE: Begot (1984)

As mercadorias, depois de embarcadas no porto de Benfica, seguiam uma estrada conhecida como Maratá, cheia de entraves tortuosos. A carroça era puxada a boi e demorava horas até chegar à referida colônia com as mercadorias vindas de Belém.

Tal situação só iria melhorar em 1880, com as obras no ramal de Benfica. O Ramal de Benfica recebeu as seguintes mudanças estruturais, que facilitaram o escoamento da produção: 20 metros de largura, 5 pontes, 46000 dormentes, $9 \mathrm{~km}$ de extensão e duas estações, localizadas da seguinte maneira: a inicial em Benfica e a final na colônia agrícola de Benevides. Os bondes que conduziam as mercadorias e as pessoas, pelo ramal de Benfica eram puxados à tração animal.

Após a instalação da EFB (1884), também, foi criada, na então estrada conhecida como Maratá, uma linha férrea até Benfica por onde circulavam "pequenos carrinhos" chamados "troles", os quais eram operados manualmente. A instalação dessa linha férrea facilitou o transporte de mercadorias até o porto de Benfica (BEGOT, 1984).

O distrito de Benfica era pouco habitado e o que dava sustento a sua população era uma olaria existente no referido local (Olaria Paraense). O produto confeccionado pela olaria era tijolo. As atividades de pesca artesanal e caça também davam sustento a tal população. A dificuldade da população na obtenção de produtos industrializados era enorme, pois os mesmos só podiam ser encontrados em Belém. 
Próximo a Benfica, havia uma comunidade denominada Murinin, muito conhecida pela fartura de camarões e outros mariscos. As pessoas que moravam na comunidade enfrentavam dificuldades maiores de acesso até Belém, já que, para chegarem à capital, precisariam se deslocar de barco até o porto de Benfica e, de lá, pegar o navio até Belém.

Em Murinin, também existiam olarias que fabricavam telhas, as quais eram comercializadas em Belém. Esses produtos seguiam de barco até o porto de Benfica, de onde eram levados de navio até a capital. Outra possibilidade consistia no embarque de tal produto no porto de Benfica, nas troles ${ }^{2}$, e seguiam na via férrea do Maratá até chegar à estrada de ferro de Bragança, onde a mercadoria era embarcada no trem, daí seguindo até Belém.

Com a inauguração do primeiro trecho da EFB, em 1884, entre a cidade de Belém e a colônia agrícola de Benevides oentão presidente da Província Visconde de Maracajú decidiu terminar o contrato de navegação entre Belém e Benfica e extinguir o ramal entre Benfica e a colônia agrícola de Benevides. Tal decisão causara fortes conseqüências negativas para a população de Benfica e Murinin que voltou ao isolamento, estando restrita a uma navegação a remo para chegar até a capital. Assim como, tiveram que ir a pé ou a cavalo de Benfica até a estação ferroviária na colônia de Benevides.

O ramal entre Benfica e a colônia de Benevides estava entregue a própria sorte, tendo boa parte de sua estrutura férrea vendida pelo governo provincial. A vegetação aos poucos tomava conta do referido trecho, o qual ficou restrito aos pisoteios de animais e das pessoas que faziam tal trajeto diariamente. Um ano após a desativação do ramal pouco restava do caminho. $\mathrm{O}$ isolamento de Benfica e Murinin era uma realidade triste que impossibilitava o progresso nas duas localidades, que muito tinham a contribuir no comercio com a capital.

O vigário da então freguesia de Benfica (padre José de Castilho), juntamente com outras autoridades locais, através de muitas reivindicações perante os governantes da época conseguiu a reativação do ramal entre Benfica e Benevides. O jornal A Província do Pará, no dia 10/07/1894, noticiou a seguinte informação: “(...) partiram para Benfica os bondes, destinados àquelle ramal, sendo anunciada esta por bastas girândolas de foguetes, vivas e enthusiasmo geral..."

A diferença entre o novo ramal e o antigo existente no referido trecho foi a construção de paradas e cocheiras ambas construídas na colônia de Benevides, no entrono da

\footnotetext{
${ }^{2}$ Tratava-se de bondes puxados por animais, espécies de carruagens que transportavam pessoas e mercadorias (CRUZ, 1955).
} 
estação ferroviária. Foram nove quilômetros acrescidos à linha principal. Seguiram-se os benefícios à população local e aos comerciantes que escovam sua mercadoria com maior fluidez até a Freguesia de Benfica.

Apesar de todas as benfeitorias desse novo ramal, tais como: transporte de pessoas, madeira, gêneros agrícolas e, sobretudo, mercadoria das olarias, em 1934, o ramal foi, definitivamente, desativado, inclusive retirado da chamada linha tronco. O saudosismo de uma viagem que se iniciava em Belém, num trem à vapor, e se findava com os bondes puxados por animais até Benfica está vivo nas memórias dos benevidenses que puderam vivenciar tais fatos históricos.

Ainda no ano de 1885 é concluído o trecho da EFB até a localidade de Apeú. Ao longo do referido trecho são criadas as paradas São Pedro, Cupuaçú e Quarta Travessa, as quais passaram a configuram o território da futura Vila de Benevides. Tal efetivação veio a se concretizar no ano de 1899 a colônia de Benevides é, de fato, elevada à categoria de Vila, estando vinculada à cidade de Belém. Posteriormente, a então Vila de Benevides se torna Distrito de Ananindeua, no ano de 1943, quando Ananindeua ganha status de município.

\section{DE COLONIA AGRÍCOLA A MUNICÍPIO DA RMB}

De colônia agrícola, que supria as necessidades de gêneros alimentícios da capital, o referido território da colônia benevidense passou a município da Região Metropolitana de Belém (RMB). A partir de 1955, praticamente, termina a área de colônia, em específico, após a construção da BR-316, que substitui a ferrovia pela via rodoviária.

A configuração espacial de Benevides enquanto município é formada a partir do antigo Engenho Aracy e Benfica (desmembrados do município de Ananindeua) e de parte do distrito-sede de Santa Isabel do Pará (TRINDADE JR, 2002). O município de Benevides ganha status de emancipado no ano de 1961. Daí em diante, Benevides toma ares de espaço onde não haveria somente traços agrários, mas passaria a incorporar alguns elementos presentes nos espaços considerados urbanos.

Por volta de 1975, o então prefeito de Benevides, Claudionor Begot, cria a área comercial de Benevides. Tal prefeito desapropriou uma grande área na sede municipal e a transformou em centro comercial. Os lotes foram doados àquelas pessoas que tivessem interesse em construir comércios em Benevides. O referido gestor público municipal realizou 
uma propaganda veiculada em Belém, informando sobre a doação de terrenos em Benevides para o referido fim. Logo vieram vários empresários com interesses em iniciar seus negócios. Claudionor Begot concedeu, na época, uma isenção de impostos de cinco anos aos interessados.

Após a desativação da EFB o transporte rodoviário ganha força e se espalha por toda a RMB. Benevides inicia seu fluxo de transporte rodoviário por volta de 1970, com caminhões que dispunham de carrocerias iguais as de ônibus. Neste período, apenas dois veículos saíam do mercado de São Brás (bairro localizado em Belém) até o centro (sede municipal) em Benevides, ao lado da antiga "casa de força" (a qual gerava energia a óleo para o município na época).

Da década de 1970 em diante, seria necessário incentivar o crescimento de Benevides através da expansão do seu sítio urbano. O ponto inicial dessa expansão se daria na sede municipal, a qual tomou o nome de bairro Centro. Abaixo podemos visualizar, na figura 7, uma imagem da Agencia do Correios, em Benevides, que data de 1984.

FIGURA 7: Agência dos correios de Benevides.

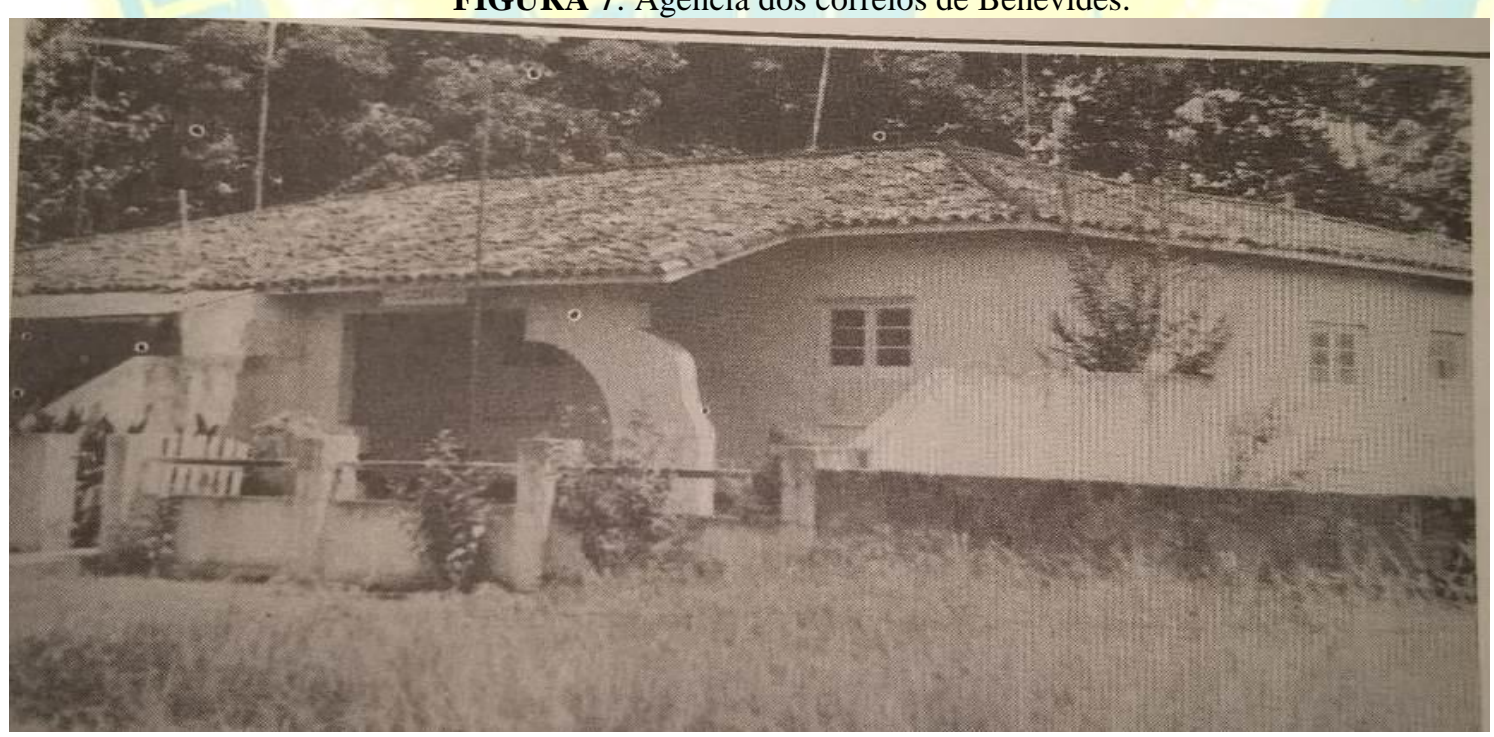

FONTE: Begot (1984).

No ano de 1972 um empresário português inicia uma linha (itinerário) que saía do município de Santa Izabel do Pará com destino a Belém, passando por Benevides. Os prefeitos que sucederam Claudionor Begot deram continuidade ao projeto da expansão do Benevides através da criação de bairros para incentivar o povoamento da cidade. 
A Prefeitura Municipal de Benevides (PMB), ao longo da estruturação do sítio urbano do município, efetivou um controle fundiário do ponto de vista legal, em que a aquisição dos lotes, pelos moradores, ocorreu mediante doação. A partir da década de 1970, diversas ruas foram abertas no município, proporcionando uma fluidez no acesso a tais lotes. A figura 8, a seguir, ilustra a prefeitura municipal de Benevides, construída na administração do antigo prefeito Osmar França (1977 a 1983), período em que a sede municipal de Benevides estava se estruturando. Tal prédio ainda mantém a mesma estrutura arquitetônica.

FIGURA8: Prédio da Prefeitura municipal de Benevides.

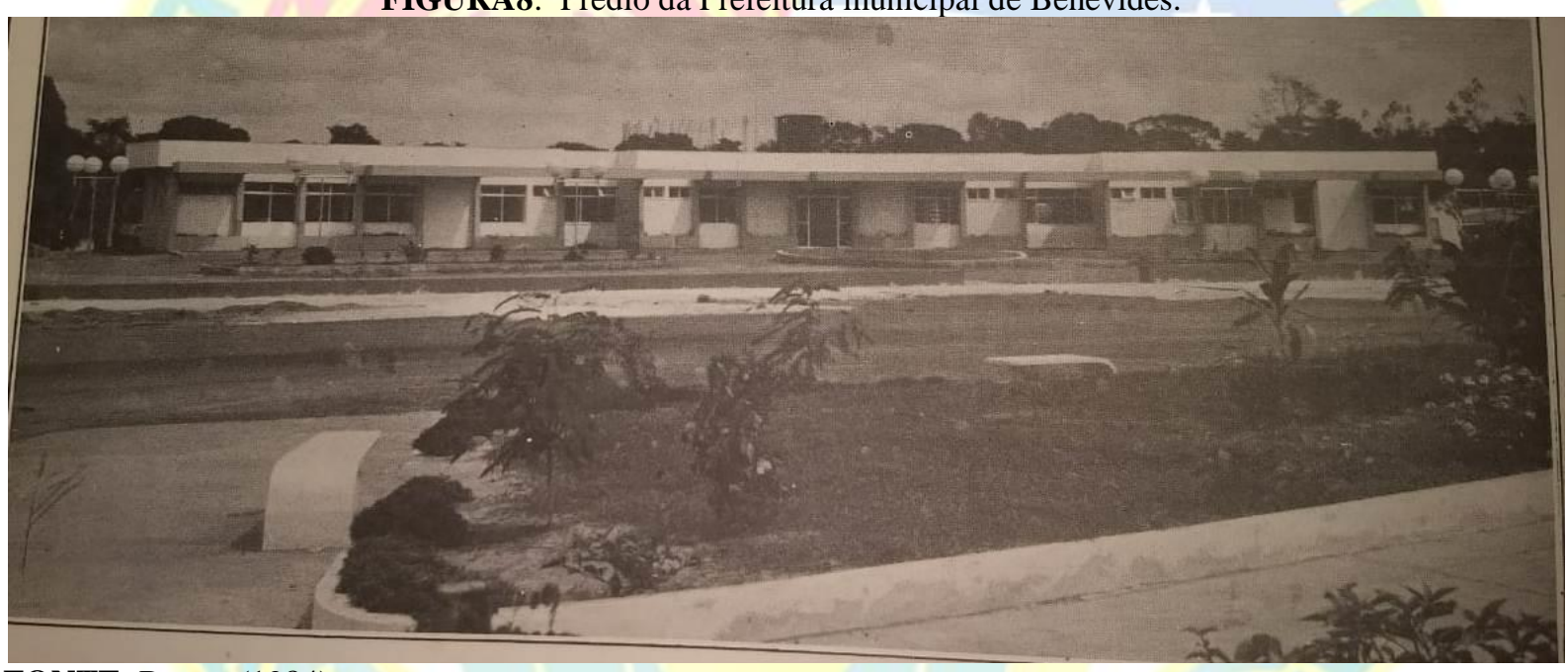

FONTE: Begot, (1984)

Organizou-se, pela PMB, uma malha urbana pré-definida, com o desenho das ruas largas e regulares, entrecortando os terrenos. Dessa forma, o ambiente urbano de Benevides se estruturou, materializando, no espaço, uma organização pautada em instrumentos legais (SOUZA, 2007).

\section{CONSIDERAÇÕES FINAIS}

A sequencia de trabalhos e estruturas que se seguiu na produção espacial de Benevides não teve o cuidado de manter totalmente preservado o legado arquitetônico do passado, fato esse que nos limita no aprofundamento de pesquisas que possam nos trazer evidencias mais reais acerca da herança deixada pela influencia da EFB.

Os estrangeiros que se instalaram na colônia agrícola de Benevides tiveram dificuldades de adaptação, porém os que prosperaram deram origem a um legado que até hoje 
permanece vivo junto às inúmeras famílias tradicionais que existem nesse município. Famílias como Solon, Begot e Rufino, que sustentaram e sustentam, ao longo dos anos, uma posição política de destaque, tal como uma sólida estrutura financeira, fruto do trabalho de seus antepassados que muito trabalharam na antiga colônia agrícola.

A produção espacial ao longo do ramal de Benfica, influenciada pela existência, no passado, de uma extensão da EFB, nos evidencia rugosidades que remontam o passado de grande produção madeireira e artigos de olaria. Os fornos, em estilos rústicos, ainda podem ser vistos em plena atividade, em uma das olarias, porém com uma capacidade de produção de telhas e tijolos bem menor.

A primeira Agência Postal (Correio) do município de Benevides data de 1984, ano em que chegou à Província do Pará o contador do Tesouro Nacional. O referido prédio ainda mantém a mesma função, porém a forma encontra-se um tanto deturpada. No entanto, mantém viva mais uma rugosidade fruto da estruturação urbana que Benevides passou a sofrer após a extinção da EFB.

No passado, a colônia agrícola de Benevides, nunca pôde incrementar em sua economia a pratica da industrialização, porém possuía uma rede de engenhos, cuja experiência era, sobretudo, peculiar aos nordestinos.

Os franceses também foram atraídos pela técnica apurada de fabricar açúcar, álcool e aguardente de cana. Um exemplo foi o francês François Paul Begot, que possuiu um grande engenho conhecido como "São Francisco".Tal francês foi considerado um pioneiro na fabricação de casas de barro (enchimento), com técnicas trazidas da França; tendo o mesmo construído onze edificações na colônia de Benevides.

A estruturação urbana, a qual Benevides passou a ter, pós extinção da EFB, obedeceu a um modelo de desenvolvimento onde o comercio e o transporte de pessoas passou a ser suprido por uma logística rodoviária. Seus gestores seguiram a expansão de tal modelo no Estado do Pará estimulando a produção automobilística no país.

O município de Benevides teve o início de sua estrutura espacial fortemente influenciada pela EFB, assim como muitos outros municípios que fazem parte do nordeste paraense. O legado patrimonial (material e imaterial), deixado pela EFB neste município nos permite entender a lógica de criação desse município, hoje, pertencente à RMB. As rugosidades espaciais como o prédio do antigo Engenho Santa Sophia, a Estação Ferroviária, a Casa dos Americanos, a Prefeitura Municipal de Benevides etc., nos permite entender que a 
historia deste município está atrelada a um passado aonde o progresso vinha pelas trilhas férreas de uma "Maria Fumaça", que trazia desenvolvimento por onde se instalava.

\section{REFERENCIAS}

CRUZ, E. A Estrada de ferro de Bragança: visão social, econômica e política. Belém: SPVEA, 1955.161f

BEGOT, C. Álbum histórico terra da liberdade. Prefeitura Municipal de Benevides (PMB), 1984.

FERREIRA, R. C. A estrada de ferro de Bragança: inventário do patrimônio ferroviário. In: SARQUIS, G. B. (org.)Estrada de Ferro de Bragança: memória social e patrimônio cultural. Belém: IPHAN-PA, 2017. 160f

SIQUEIRA, J. L. F. O caminho de ferro e seus ramais. In: SARQUIS, G. B. (org.)Estrada de ferro de Bragança: memória social e patrimônio cultural. Belém: HIPHAN-PA, 2017. $160 f$.

SANTIAGO, T. P.; OLIVEIRA, Z. M. O desenvolvimento do município de Benevides na década de 1960 até os dias atuais. Monografia de Especialização. Curso de Pós-graduação EME ensino de história do Brasil - LATO SENSU. Universidade do Vale do Acaraú (UVA). Belém, 2005. 60f

SOUZA, L. A. de. Paisagem urbana e qualidade de vida no município de Benevides-PA. Trabalho de Conclusão de Curso (TCC). Instituto de Filosofia e Ciências Humanas (IFCH)/UFPA. Belém, 2007.89f

PREFEITURA MUNICIPAL DE BENEVIDES. Documentos oficiais. Benevides, 2007.

TRINDADE JR. S. C. da. A cidade dispersa: os novos espaços de assentamentos em Belém e a reestruturação metropolitana. São Paulo: 1998. Tese (Doutorado em Geografia Humana). Faculdade de Filosofia, Letras e Ciências Humanas, Universidade de São Paulo. $395 f$. 